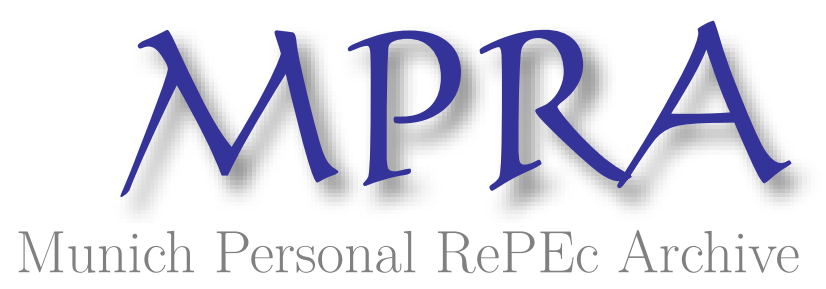

\title{
Women's employment during pregnancy and after the first birth: Occupational characteristics and work commitment
}

Desai, Sonalde and Linda J., Waite

The Population Council, The University of Chicago

1991

Online at https://mpra.ub.uni-muenchen.de/111172/

MPRA Paper No. 111172, posted 24 Dec 2021 08:37 UTC 


\title{
WOMEN'S EMPLOYMENT DURING PREGNANCY AND AFTER THE FIRST BIRTH: OCCUPATIONAL CHARACTERISTICS AND WORK COMMITMENT*
}

\author{
SonALDE Desai \\ The Population Council
}

\author{
LINDA J. WAITE \\ The University of Chicago
}

\begin{abstract}
We examine the argument that predominantly female occupations attract women because they are relatively easy to combine with family responsibilities. Some traditionally female occupations offer relatively low penalties for labor force withdrawal, but other "female" occupations reduce the costs of employment to mothers by facilitating the combination of worker and mother roles. We test the hypothesis that a woman's response to the characteristics of her occupation and to other factors depends on her preference for employment vs. homemaking over the long run. Using data from the National Longitudinal Survey of Youth, the analysis focuses on the period from the year prior to the first birth through the two years following the birth as the time of maximum conflict between employment and child rearing. We find no effect of occupational sex composition on the likelihood that prospective or recent mothers are employed. Occupational characteristics that raise the cost of labor force withdrawal (high education, wages, and job-specific training) tend to decrease the probability of women's withdrawal from work, as do nonmonetary occupational characteristics. All women respond to the cost of labor force withdrawal, but women with low work commitment also respond to financial pressures and convenience of the work setting.
\end{abstract}

A lthough women have made rapid gains in their level of labor market activity, they have made much less progress in attaining wage parity with men (Smith and Ward 1989). Despite some improvement, women remain segregated in a small number of predominantly female occupations (Beller 1985; Jacobs 1989). Possible explanations for the continued occupational segregation of women include socialization during childhood, discrimination and tracking, and conscious choice for reasons of convenience (Reskin and Hartmann 1986). We examine the last explanation - that women choose primarily female occupations because they are convenient for women with family responsibilities. According to this reasoning, occupations attract women workers by making it easy and relatively costfree for them to withdraw from the labor force while their children are young (Polachek 1979, 1987). Predominantly female occupations also

${ }^{*}$ Direct all correspondence to: Linda J. Waite, Population Research Center, Ogburn/Stouffer Center, NORC and University of Chicago, 1155 E. 60th Street, Chicago, IL 60637. Paper presented at the annual meeting of the Population Association of America, Baltimore, 1989. This research was funded by Center Grant P50-HD12639 and Post-Doctoral Training Grant No. 1-T32-HD07329-01 from the Center for Population Research, National Institute of Child Health may facilitate the combination of employee and mother roles.

We examine women's employment during pregnancy and in the two-year period following the first birth. We focus on the first birth because the birth of a child, especially the first child, greatly increases what economists call the "shadow price of time in the home," i.e., the value to the family of women's time in homemaking. Pregnancy and childbirth impose psychological and physical strains on women; previous research has suggested that the effect of fertility on female labor force participation is greatest at this time (Hout 1978; Cramer 1980). Hence, if occupational characteristics have any effect on a woman's ability to combine family with work, these effects should be strongest during pregnancy and immediately following the birth of the first child.

We test hypotheses about the characteristics of women's occupations and preferences for work

and Human Development, and by Grant No. J-9-J-70091 from the Department of Labor. We thank Christina Witsberger, Christine Peterson, and Diane Macunovich for data file preparation, and Lisa Meredith for research assistance. We benefited from comments by Phyllis Moen and Annemette Sorensen and reviewers of earlier drafts. We also thank Arleen Leibowitz for her collaboration and advice on the project from which this research was drawn. 
and their effects on work before and after the birth. We argue that some traditionally "female" occupations offer relatively low penalties for labor force withdrawal, but that other "female" occupations reduce the costs of employment to mothers by facilitating the combination of worker and mother roles. We test the hypothesis that a woman's response to characteristics of her occupation and other factors depends to some extent on her preference for employment vs. homemaking over the long run.

\section{THEORETICAL FRAMEWORK}

Much of the literature on sex segregation in labor markets has suggested that certain occupations are especially compatible with family responsibilities (Rosenfeld and Spenner 1990), making them attractive to women, who tend to be responsible for family and homemaking duties even when they work (Spitze 1986; Ross 1987). According to this argument, this compatibility results in a concentration of women in these occupations (Reskin and Hartmann 1986; Polachek 1979).

Women who have - or expect to have spouses and/or children may consider their current or future family responsibilities when choosing an occupation. First, women who do not expect to work continuously following childbearing may select occupations that are relatively easy to leave and re-enter. These occupations - which may provide adequate to generous starting salaries - may assess lower penalties for labor force withdrawal, either through lower rewards for experience (Polachek 1979, 1987), or through fewer requirements for job-specific training (Wolf and Rosenfeld 1978) compared to other occupations.

Women who expect to work continuously following childbearing may select occupations that offer nonmonetary benefits, like flexible hours or safe and physically undemanding work. These nonmonetary benefits may make it easier to combine work and family. Some scholars argue that women receive low wages relative to men with comparable job-related characteristics because women are willing to trade off wages for these nonmonetary benefits (Filer 1985; Hudis 1976). In a recent controversial paper, Schwartz (1989) suggested that by providing such nonmonetary benefits, employers may be able to encourage women to return to work relatively quickly following childbirth.

Both of these mechanisms could explain women's concentration in a relatively small number of occupations. However, predominantly female occupations are not homogeneous on these dimensions: Some may have relatively low opportunity costs of labor force withdrawal, while others may provide nonmonetary benefits. If so, women who plan to work while they have young children may use different criteria when selecting an occupation than do women who plan to withdraw from the labor force. And women who prefer to work over the long run may respond to different characteristics of occupations in deciding on employment during pregnancy and after the birth of a child.

Not all women consciously "choose" their occupations, and many women move from one occupation to another over their work lives, quite commonly between "female" and "male" occupations (Jacobs 1989). We expect that women who find themselves in an occupation that makes it easy to combine work and childrearing or in an occupation that penalizes labor force withdrawal, would be more likely to return to work after a birth than other women, regardless of their reasons for selecting the occupation in the first place. This relationship may be weakened by constraints on women's occupational choice, like actions of employers or characteristics of the labor market.

\section{Preference for Employment}

Some women prefer to work exclusively in the home over the long run, whereas others prefer to combine work and family. ${ }^{1}$ This underlying preference for work over other activities is often called work commitment, or subjective orientation towards work. Work commitment indicates the importance of market work in an individual's life, but is distinct from labor force attachment (Bielby and Bielby 1984; Rosenfeld and Spenner 1986). While women with a high degree of labor force attachment are more likely to be continuously employed, employment, by itself, does not imply a high level of work commitment - some women who would prefer not to work are propelled into the labor force by financial pressures, and some women who prefer to work may be unable to work because of family responsibilities (Moen and Smith 1986).

Work commitment also seems to be distinct from occupational attainment. Both Rosenfeld

\footnotetext{
${ }^{1}$ Although women could prefer to work and not have children, this is a relatively rare response among the young women in the NLSY sample. Of the women who had no children in 1979, most (92 percent) expected to have children.
} 
and Spenner (1986) and Gerson (1985) suggested that although work commitment for women rises with higher occupational status, many women report high levels of commitment to work despite holding low-status jobs. Work commitment reflects both personal preferences and the importance of intrinsic features of work such as how important and interesting it is and extrinsic features like relationships with co-workers.

To the extent that women workers are heterogeneous with some having an underlying preference for employment over alternative activities, any model of women's labor force behavior must incorporate this heterogeneity. Sixty-two percent of the young women respondents in our data set prefer to work over the long run, and 38 percent prefer homemaking.

Work commitment may predict women's employment, but it may also condition the effect of occupational characteristics on employment. Compared to women with lesser work commitment, women with strong work commitment may be less responsive to characteristics of occupations that make it easy (or hard) to combine work with childrearing.

Thus, occupations may encourage women's labor force participation surrounding a birth in two ways: by making it relatively easy to combine work with motherhood; or by making it difficult to stay away from work. We first present our hypotheses about occupational characteristics that increase the costs of remaining away from work for extended periods. Then we discuss occupational characteristics that facilitate a new mother's return to work.

\section{Factors That Discourage Staying Away} From Work

Some occupations may increase the chances that their female incumbents return to work following a birth by raising the costs of time away from the job. Certain personal characteristics of workers index costs of time away from work, e.g., a women's earnings or earnings potential represents the opportunity cost to her of time spent at home taking care of her child rather than working. The higher the opportunity cost, the greater the chance that she will return to work. In addition, a woman's ability to acquire high quality, dependable care for her young child increases with her earnings (Leibowitz, Waite, and Witsberger 1988). Thus, we hypothesize that the higher a woman's earnings in the year prior to the birth, the more quickly she will return to work afterward.
The impact of education on return to work is more complex and the net effect difficult to predict. Historically, highly educated women have been more likely to work than women with less education when they did not have young children and less likely when young children were present (Leibowitz 1974). This pattern has weakened recently, but may persist. On the other hand, highly educated women may face greater depreciation of job-related skills from time out of the labor force compared to women with less schooling. This depreciation would encourage their return to work.

We hypothesize that women in occupations that require substantial job-specific training will return to work quickly to minimize the depreciation of their work skills. In addition, the more job-specific skills a woman has, the stronger the incentive to keep that job, perhaps by returning quickly after childbearing. A woman with general training can more easily quit her current job and seek another when her child is older.

\section{Factors That Facilitate Combining Motherhood and/or Pregnancy With Work}

Because flexibility of work schedules helps mothers meet the often conflicting demands of a young child and a job (Glass and Camarigg 1991), we hypothesize that women in occupations that offer part-time or part-year work are more likely to return to work following a first birth than women in occupations that offer primarily full-time and full-year schedules.

The presence in an occupation of mothers of young children signals something about the ease with which women in this occupation can combine work and parenting roles. These occupations may offer flexible work schedules on a dayto-day basis, they may offer social support for working mothers, or they may allow women to work at home or to care for young children on the job. Thus, we hypothesize that the more mothers of young children in an occupation, the more likely a new mother in that occupation will return to work following her first birth.

Women may find it difficult to continue work during pregnancy if their work is physically demanding. Hence, women who are employed in occupations that are not physically taxing and require less strength for performance of job duties may find it easier to continue working during late pregnancy. 


\section{Effect of Preference for Employment}

Finally, evidence suggests that women differ in their preferences for employment vs. other activities, especially homemaking (Heckman and Willis 1977). Women who prefer to be employed over the long run tend to make investments in training (both formal and on-the-job) that pay off later in higher wages (Shaw and Shapiro 1987). Women's early preference for paid employment appears to predict later behavior quite well (Rexroat and Shehan 1984).

We expect that women who prefer to be employed over the long run will weigh the characteristics of their jobs and their situations differently than will women who prefer to be full-time housewives. Rexroat and Shehan (1984, p. 357) concluded that the employment behavior of women who want to remain at home may be a temporary response to changes in their domestic roles. They found that fertility and marital status affect employment only for women who prefer to be homemakers, and have no effect for women who prefer employment.

We hypothesize that the impact of both occupational characteristics and financial need on women's employment during pregnancy and after the first birth depends on work commitment. We expect both factors to matter less for women who prefer employment over the long run than for those who prefer to be full-time homemakers.

\section{Processes Influencing Employment Before and After Birth}

The physical and emotional demands made on the mother by events leading up to and following the birth of a child are not homogeneous. We outline four distinct periods during pregnancy and following the birth in which we expect different processes to affect a woman's employment.

The first two trimesters of pregnancy. Most women are physically capable of working at most jobs during early and middle pregnancy. Women who leave work during the first two trimesters of pregnancy have probably resigned, as few employers provide long (unpaid) leaves prior to childbirth. The decision to quit a job is influenced by factors like cost of time away from work, convenience of work setting, and financial need. We expect that early exits from the labor force will be most strongly (and inversely) affected by the cost of withdrawing from the labor force, so that high education, high wages, and job-specific training requirements would all re- duce the rate of job-leaving during this period. In contrast, the scheduling flexibility of an occupation that makes it easy to combine work and motherhood may be relatively less important in pregnancy because the woman has not yet faced the practical problems of childrearing.

The third trimester of pregnancy. Job exits during the last trimester of pregnancy increasingly reflect short-term rather than long-term exits (Klerman 1990). Although many women, especially those who intend to return to their jobs, work during most of pregnancy, medical considerations may prompt women to leave work in the last trimester, blurring the distinction between women who want to withdraw from the labor force and women who have to for health reasons. In addition, advanced pregnancy may make performance of job tasks demanding high levels of physical effort difficult or impossible.

The first three months after the birth. Most women who return to their pre-birth jobs return relatively soon after the birth. Few women hold jobs that allow them to take more than three months leave following the birth. In fact, National Longitudinal Survey of Youth data on maternity leaves collected in 1983 showed that the modal length of maternity leave for women who took leave was six weeks. We expect that these early returns to work respond to costs of labor force withdrawal, especially education, wages, and job-specific training. Additionally, characteristics of the occupation that make it easier to combine work and motherhood, like a flexible work schedule, may be important to women's employment decisions at this juncture.

More than three months after the birth. If women do not return to work within three months of the birth, they tend to return to a different job. The longer a woman has been out of the labor force, the less relevant the characteristics of her past occupation for future job choices. For this reason, occupational characteristics during pregnancy should have progressively smaller effects on return to work with time since the birth.

\section{DATA}

Our analyses use data from the National Longitudinal Survey of Youth (NLSY). Designed by the Center for Human Resource Research of the Ohio State University and fielded by NORC, the NLSY began in 1979 with a national probability sample of individuals who were aged 14-21 on January 1, 1979 and living within the United States or who were on active military duty out- 
side the United States. A total of 12,686 persons completed interviews in 1979 . These included an oversampling of Hispanics, blacks, nonblack and non-Hispanic economically disadvantaged individuals, and a separate sample of 1,280 persons on active duty in the military.

In the baseline year, the respondents provided detailed information on family background, schooling and training history, work history, marital and fertility status, current job, earnings and income, and a series of attitudinal measures. Respondents were reinterviewed in every subsequent year to the present, with excellent retention of the original sample; our analyses use data through 1986.

To test our hypotheses, we focus on women who had a first birth between the 1979 interview and the 1985 interview. These women had an age at first birth varying from 15 to 27 years. This allows us to observe the employment behavior of the women for one year prior to first birth and for at least one year after the birth. The resulting sample is representative of the experiences of women who have children early and at average ages, but underrepresents late childbearers. ${ }^{2}$

We concentrate on the last occupation of the woman before childbirth, arguing that this occupation indicates the type of work available to her and also reflects her occupational choices in anticipation of pregnancy (Darian 1975).

\section{Sample}

The sample consists of the 1,158 women who had a first birth between the first interview in 1979 and the 1985 interview, who worked in the year before the first birth, and who worked at least 20 hours per week in the last job held before the birth and who worked at least 9 weeks at that job. We exclude women who worked less than 20 hours per week or less than 9 weeks at the last job held prior to birth because the NLSY does not provide detailed occupational information for these women. ${ }^{3}$ The analysis of employment during

${ }^{2}$ Since higher education and market orientation lead to delayed first birth, our sample is not fully representative of the occupations women engage in. In particular, women in occupations requiring high training are more likely to be underrepresented.

${ }^{3}$ To obtain occupational information, we selected women using two criteria: (1) women who worked in the year prior to the birth; and (2) women who worked at least 9 weeks and 20 hours per week in their last job (NLSY did not collect occupational information for women who worked less than that). Although these pregnancy uses the 1,055 women of these 1,158 who were employed at some point between conception and the birth, omitting those who worked in the year prior to the birth but not after the conception.

\section{Dependent Variables}

The NLSY provides a week-by-week work history for each respondent, constructed from questions asked in each year about the beginning and ending dates for each job during the previous year. Respondents were also asked the starting and ending dates of any gaps in work that occurred while they were employed by a particular firm. They reported on "any periods of a full week or more during which [they] did not work for employer, not counting paid vacations or paid sick leave." We merge this employment history for years 1978 through 1986 with information on the date of birth of the first child to construct a history of work surrounding pregnancy.

We analyze two dependent variables: elapsed weeks of gestation when the woman stopped working, and weeks between the first birth and the mother's return to work. Our data on maternity leave are based on an employment history that provides: (1) time at work; (2) time employed but not at work; (3) time either out of the labor force or looking for work. Time spent on paid vacation or sick leave was counted as time employed and at work. Respondents were instructed to report short absences like "maternity leave with pay" as time on the job. Thus, a large share of women - 21 percent - report no gap in employment when their first child was born.

However, information on maternity leave collected in the NLSY in 1983 offers some insight into this restriction on the employment data. In 1983 , female respondents were asked if they had worked at all during their last pregnancy. If they had, they were asked if their employer offered maternity leave, if they took such leave, and when they returned to work following the birth. We examined women in our sample who also responded to the 1983 questions on maternity leave.

criteria bias our sample toward women with a strong market orientation, the bias due to missing occupational information appears to be relatively minor. Only 170 women were excluded because of missing occupation data. Results for the effects of individual characteristics on women's employment for the full sample (consisting of all women who worked in the year prior to the birth) were similar to results for our current sample. 
Table 1. Descriptive Statistics for Variables in the Analysis: NLSY Women Employed During Pregnancy 1979-1985

\begin{tabular}{|c|c|}
\hline Variable & Mean \\
\hline \multicolumn{2}{|l|}{ Background Characteristics: } \\
\hline White (nonblack, non-Hispanic) & .571 \\
\hline Black & .237 \\
\hline Hispanic & .192 \\
\hline Married at birth of child & .653 \\
\hline Not married at birth of child & .347 \\
\hline Age at birth of child & $\begin{array}{r}21.120 \\
(2.399)\end{array}$ \\
\hline$<12$ years of school completed & .196 \\
\hline$=12$ years of school completed & .546 \\
\hline$>12$ years of school completed & .258 \\
\hline Other family income & $\begin{array}{l}\$ 6619.791 \\
(6477.905)\end{array}$ \\
\hline Other family income (log) & $\begin{array}{r}6.569 \\
(3.849)\end{array}$ \\
\hline Hourly wage at last job & $\begin{array}{r}3.230 \\
(1.409)\end{array}$ \\
\hline Hourly wage at last job (log) & $\begin{array}{l}1.402 \\
(.269)\end{array}$ \\
\hline Missing Wage & .095 \\
\hline Plan to work at age 35 & .622 \\
\hline \multicolumn{2}{|l|}{ Occupational Characteristics: } \\
\hline In predominantly female occupation & .624 \\
\hline In occupation with many mothers & .504 \\
\hline $\begin{array}{l}\text { In occupation with many part-time } \\
\text { female workers }\end{array}$ & .540 \\
\hline $\begin{array}{l}\text { In occupation with many part-year } \\
\text { female workers }\end{array}$ & .522 \\
\hline Specific vocational preparation & $\begin{array}{l}4.242 \\
(1.423)\end{array}$ \\
\hline Strength requirement & $\begin{array}{l}2.056 \\
(.681)\end{array}$ \\
\hline Physical demand & $\begin{array}{l}1.665 \\
(.650)\end{array}$ \\
\hline Number of cases & 1,058 \\
\hline
\end{tabular}

Note: Numbers in parentheses are standard deviations.

Only 9 percent of the women who reported that they were employed in the week prior to delivery actually returned to work in the week following delivery, although 74 percent of these women reported no gap in employment under our definitions. Nevertheless, according to the 1983 interview, women in our data set who reported no gaps in employment did return to work fairly quickly -83 percent returned within the first three months after the birth.
Because we can't identify paid time away from work in the work history data, we put all women who returned to work within the first three months following childbirth into a single, short maternity leave, category. After that point, the data distinguish quite well those women not on the job, and we treat week of first return to work as a continuous variable.

Since we do not know the date of conception, we assume that all births are full term, i.e., born after 39 weeks of gestation. ${ }^{4}$ Thus, to calculate the elapsed weeks of gestation at the time the woman left work, we count backwards from birth.

\section{Individual and Family Characteristics}

In our analysis, we include the following characteristics of the woman: her race/ethnicity, marital status, age, education at childbirth, family income excluding woman's earnings and AFDC payments, and her wage in the last job held during pregnancy. Definitions of variables are shown in the Appendix and descriptive statistics are provided in Table 1.

We have suggested that the effects of individual and occupational characteristics on a woman's labor force participation depend on her preference for employment over the long run. This notion of differentiating between women with high and low labor force commitment is similar to the concept of unobserved heterogeneity used in the economics literature. This heterogeneity is usually thought to reflect differences in women's labor force attachment (Flinn and Heckman 1982). However, the economics literature usually distinguishes women according to their actual labor force behavior, which may not be consistent with their long-run preferences for employment vs. work in the home.

We directly measure women's preference for employment vs. homemaking over the long run. In each year, the NLSY asked respondents, "What would you like to be doing when you are 35 years old?" Using responses to this question at the interview before birth, we divide women into those who want to work at age 35 , whom we classify as having high work commitment, and those who prefer to be at home or to be engaged in some other activity, whom we characterize as having low work commitment.

This definition of women's work commitment assumes that this preference is relatively stable

\footnotetext{
${ }^{4}$ About 74 percent of all deliveries occur between weeks 37 and 41 of the pregnancy (Guttmacher 1956).
} 
over time, which may not be the case (Gerson 1985). However, we are assuming this stability over a very short period, and prior research (Bielby and Bielby 1984) has suggested that women's work commitment is not affected by childbearing.

\section{Occupational Characteristics}

Characteristics of occupations come from two sources: (1) the Current Population Survey; and (2) the Dictionary of Occupational Titles. After pooling data from the 1979 through 1982 Current Population Surveys, we calculated average characteristics for each three-digit Census occupational category: percent female in the occupation; percent of women in the occupation who worked part-time, i.e., fewer than 30 hours per week; percent of women in the occupation who worked part-year, i.e., less than 48 weeks per year; and percent of all incumbents in the occupation who are women with own children under three years of age. ${ }^{5}$ Because these variables are highly skewed with long right tails, we dichotomized each variable at or near the midpoint of each distribution (see Appendix).

The second set of occupational characteristics comes from the Dictionary of Occupational Titles (4th ed.). Using a data tape matching Dictionary of Occupational Titles (DOT) data to census occupation codes (Roos and Treiman 1980), we matched the information on occupational characteristics to occupational categories in NLSY data. ${ }^{6}$ Since even three-digit Census detailed occupation codes are too broad in some instances, we used a seven-digit code based on the census occupation, industry, and class of worker classification developed by Temme (1975). This resulted in 574 occupational categories.

We used three DOT-based occupational characteristics in our analysis: specific vocational preparation, strength requirement of the occupation, and physical demands. Definitions of variables are presented in the Appendix. Descriptive statistics are presented in Table 1.

\footnotetext{
${ }^{5}$ We pooled the CPS because the characteristics of interest vary little over this period and some occupations were not adequately represented in any one survey. This strategy has the added benefit of covering almost all the years in which the women in our sample were having their first births and deciding about returns to work.

${ }^{6}$ This tape maps over 12,000 DOT categories into 574 census occupation-industry categories by taking a weighted average of each DOT characteristic for the set of DOT occupations falling into each broader census category.
}

\section{METHODOLOGY}

We analyzed the data using two different eventhistory analyses - a discrete-time hazard model estimated using logistic regression (Allison 1982), and a continuous-time, piece-wise constant, exponential hazards model (Tuma and Hannan 1984). Because we could not determine the exact return time for women who returned to work within three months of the first birth, we first analyze the return to work with a logistic regression model using a dummy variable for return to work within the first three months. For women who did not return to work within the first three months following the birth, we model the week of return to work in a continuous-time framework. Work during pregnancy is also analyzed using a continuous-time hazard model. Because we argue that the effects of covariates on leaving work in pregnancy and returning to work after childbirth are not constant throughout the time interval, we use a piece-wise constant exponential model that assumes that the baseline hazard remains constant within a short period, but changes between periods. ${ }^{7}$ The effects of covariates are assumed to be constant within a time period but vary between periods. Models are estimated using the computer program RATE (Tuma 1980).

\section{RESULTS}

\section{Patterns of Employment Before and After the First Birth}

The hazard of leaving work during pregnancy (not shown) is relatively constant over the first six months of pregnancy, but rises sharply in the last trimester. This pattern - together with theoretical considerations - underlies our decision to analyze these two periods separately. In a normal pregnancy, very few maternity leaves begin in the first two trimesters. Hence, women who leave work in this interval tend to leave that job permanently. These women plan to stay out of the labor force at least for a while and perhaps return at some future date. On the other hand, women who leave work in the last trimester, especially in the last month of pregnancy, may be planning a labor force withdrawal or they may simply be taking a short maternity leave.

Figure 1 shows the hazard of returning to work after the first birth. This hazard is nonmonotonic,

\footnotetext{
${ }^{7}$ After experimenting with different intervals, we chose intervals over which the effects of covariates remained approximately constant.
} 


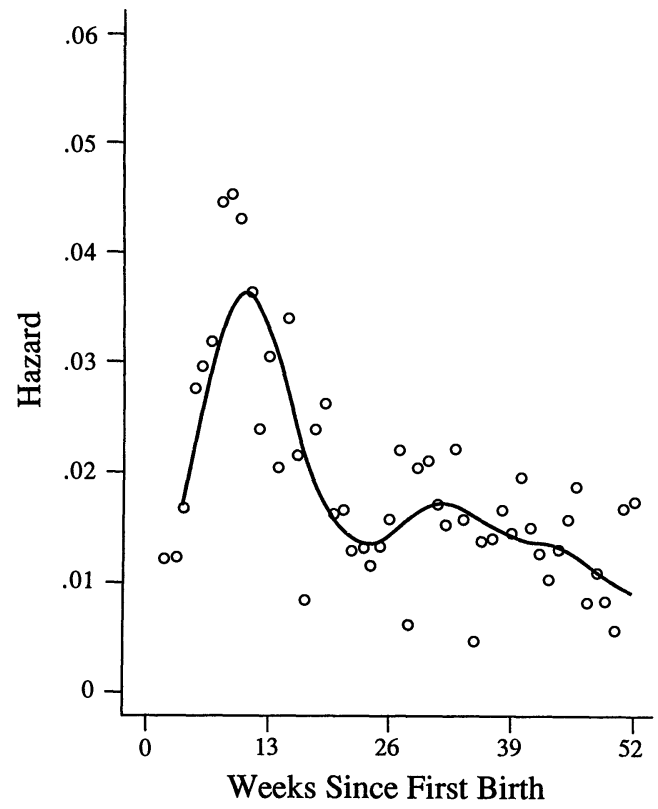

Figure 1. Hazard of Returning to Work by Weeks Since First Birth

first increasing with time to a peak at about 13 weeks after the birth and then declining. The hazard remains relatively stable in the second year after the birth (not shown). This nonmonotonic duration dependence in the hazard supports our use of a partially-parametric modelling strategy.

About 43 percent of the new mothers in our sample had returned to work within three months of the birth of their first child, and 69 percent had returned to work within 12 months. Of the women observed for three or more years, 86 percent had returned to work. These figures are higher than national figures (U.S. Bureau of the Census 1986), which show labor force participation rates of about 57 percent for mothers of a first child born in the last year. However, our sample consists of market-oriented women who were employed in the year before birth, worked at least 20 hours per week, and were employed for at least 9 weeks at their last job. Among all women in the NLSY sample who had a first birth between 1979 and $1986(\mathrm{~N}=1,837)$, labor force participation rates were similar to the national figures.

Figure 2 indicates that the hazard of returning to work is higher for women with long-run plans for employment, and this differential persists over most of the first year. (We do not plot returns within two weeks of the birth because these are primarily paid leaves).

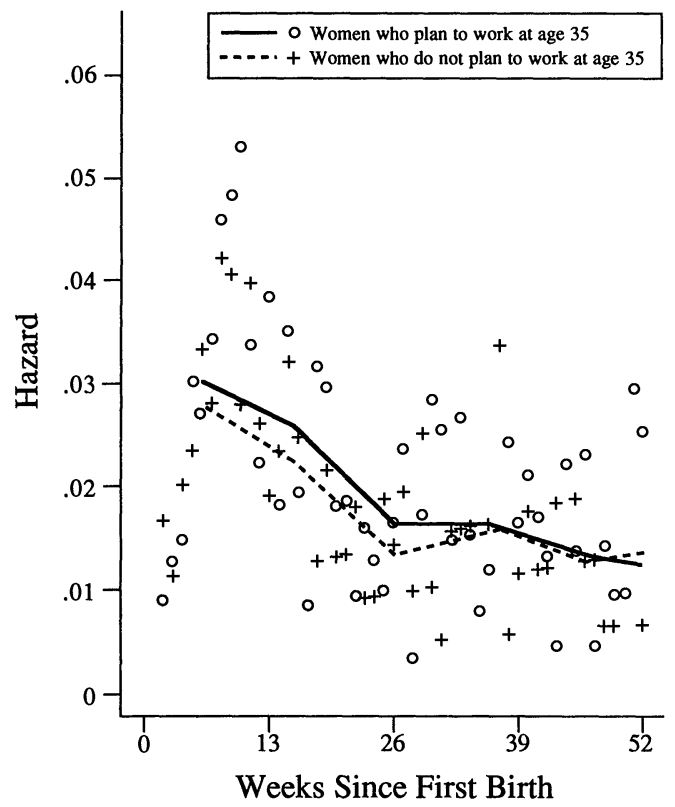

Figure 2. Hazard for Returning to Work by Weeks Since First Birth and Work Commitment

Tables 2 through 4 present the results of the multivariate analyses. Table 2 contains models for leaving work during pregnancy, Table 3 presents models of returning to work following the birth, and Table 4 gives results for returns to work within 3 months of the birth estimated separately for those who do and do not plan to work over the long run. We analyzed women's leaving work during pregnancy (Table 2), and women returning to work after 3 months (Table 3 ), using a piece-wise constant exponential hazard model with the effects of covariates constant within periods and allowed to vary across periods. ${ }^{8}$ Models for women who returned to work within 3 months (the first set of models in Table 3), were estimated using logistic regression.

"Model 1" in each table presents what we consider the basic model and includes characteristics of the woman and her family. Model 2 replaces the measure of whether the respondent's last occupation was predominantly female with detailed measures of the woman's occupation; Model 3 adds presence of mothers in the occupation to Model $2 .^{9}$

\footnotetext{
${ }^{8}$ Table 2 estimates the probability of leaving work, whereas Table 3 estimates the probability of returning to work, and hence, in general, a given variable will have opposite signs in these two tables.

${ }^{9}$ We report statistical significance for one-tailed
} 
Table 2. Effect of Selected Independent Variables on Women's Leaving Work During Pregancy: NLSY Women Employed During Pregnancy, 1979-1985

\begin{tabular}{|c|c|c|c|c|c|c|}
\hline \multirow[b]{2}{*}{ Independent Variable } & \multicolumn{3}{|c|}{ 0-6 Months of Gestation } & \multicolumn{3}{|c|}{ 6-9 Months of Gestation } \\
\hline & Model 1 & Model 2 & Model 3 & Model 1 & Model 2 & Model 3 \\
\hline Constant & -2.007 & -2.664 & -2.538 & -.388 & -.505 & -.363 \\
\hline Black & .198 & .206 & .198 & .462 & .018 & .011 \\
\hline Hispanic & .105 & .108 & .099 & -.109 & -.141 & -.153 \\
\hline Not married at birth of child & $.637^{* *}$ & $.589^{* *}$ & $.583^{* *}$ & .008 & -.024 & -.032 \\
\hline Age at birth of child & -.046 & -.027 & -.027 & $-.072^{*}$ & $-.067^{*}$ & $-.067^{*}$ \\
\hline$<12$ years of school & $.438^{* *}$ & $.389^{* *}$ & $.389^{* *}$ & .076 & .041 & .046 \\
\hline$>12$ years of school & $-.403^{* *}$ & $-.366^{* *}$ & $-.363^{* *}$ & -.079 & -.045 & -.042 \\
\hline Other family income (log) & $.047^{*}$ & $.049^{*}$ & $.048^{*}$ & -.003 & .000 & .000 \\
\hline Last wage (log) & $-1.249^{* *}$ & $-1.034^{* *}$ & $-1.037^{* *}$ & -.003 & $-.701^{* *}$ & $-.704^{* *}$ \\
\hline Missing wage & $.417^{*}$ & .292 & .304 & $-.761^{* *}$ & -.271 & -.260 \\
\hline Plan to work at age 35 & -.019 & -.036 & -.035 & $-.273^{* *}$ & $-.273^{* *}$ & $-.272^{* *}$ \\
\hline In predominantly female occupation & -.165 & - & - & .046 & - & - \\
\hline Specific vocational preparation & - & $-.122^{* *}$ & $-.130^{* *}$ & - & $-.090^{*}$ & $-.101^{*}$ \\
\hline Many part-year workers & - & .006 & .008 & -.107 & -.172 & -.174 \\
\hline Many part-time workers & - & .141 & .141 & - & .100 & .099 \\
\hline Strength requirements & - & $.240^{* *}$ & $.201^{*}$ & - & .134 & .087 \\
\hline Physical demands & - & -.118 & -.096 & - & .076 & .110 \\
\hline Many mothers in the occupation & - & - & -.078 & - & - & -.109 \\
\hline Number of cases & 1,055 & 1,055 & 1,055 & 699 & 699 & 699 \\
\hline Number of women who left work & 356 & 356 & 356 & 306 & 306 & 306 \\
\hline$\chi^{2}$ & 303.19 & 332.54 & 333.50 & 303.19 & 332.54 & 333.50 \\
\hline Degrees of freedom & 23 & 31 & 33 & 23 & 31 & 33 \\
\hline
\end{tabular}

${ }^{*} p \leq .05 \quad{ }^{* *} p \leq .01$

Note: Models are estimated using a single piece-wise constant, exponential hazard model.

\section{Sex Composition of the Occupation}

The literature on occupational sex-segregation advances two competing hypotheses accounting for women's choice of predominantly female occupations: (1) they plan to withdraw from the labor force, at least while their children are young; and (2) these occupations provide nonmonetary benefits that presumably make it easy to combine work with childrearing. If women choose predominantly female occupations because these occupations have low opportunity costs of withdrawal, then women in these occupations should be more likely to withdraw during pregnancy and after the first birth. On the other hand, if women choose traditionally female occupations because

tests for all coefficients for which we hypothesize the direction of the effect. For all others, we report significance levels for two-tailed tests. these occupations provide nonmonetary benefits, then women in these occupations may be more likely to continue to work during and after pregnancy. Because these theories suggest opposite effects of the sex composition of the occupation on employment, we make no predictions about their size or sign.

Of course, women's occupational choices are constrained, for example, by discrimination, socialization, and labor demand. A sizable proportion of women move between traditionally female, mixed, and traditionally male occupations over their adult lives, and both men and women end up in jobs without much active "choice." Regardless of how women end up in an occupation, characteristics of that occupation will influence employment choices before and after a birth.

In fact, Tables 2 and 3 show no effect of the sex composition of an occupation on women's labor force participation either during pregnancy 
Table 3. Effect of Selected Independent Variables on Women's Return to Work Following First Birth: NLSY Women Employed in Year Before First Birth, 1979-1985

\begin{tabular}{|c|c|c|c|c|c|c|c|c|c|}
\hline \multirow[b]{2}{*}{ Independent Variable } & \multicolumn{3}{|c|}{ Return Within 3 Months ${ }^{\mathrm{a}}$} & \multicolumn{3}{|c|}{ Return Within 3-11 Months ${ }^{b}$} & \multicolumn{3}{|c|}{ Return Within 12-24 Months ${ }^{\mathrm{b}}$} \\
\hline & Model 1 & 1 Model 2 & Model 3 & Model 1 & Model 2 & Model 3 & Model 1 & Model 2 & Model 3 \\
\hline Constant & -2.779 & -2.832 & -2.937 & -5.064 & -5.102 & -5.126 & -3.792 & -3.604 & -3.559 \\
\hline Black & .123 & .119 & .123 & .057 & .064 & .068 & -.085 & -.079 & -.092 \\
\hline Hispanic & .159 & .156 & .179 & -.052 & -.052 & -.045 & -.097 & -.104 & -.121 \\
\hline $\begin{array}{l}\text { Not married at birth } \\
\text { of child }\end{array}$ & $-.846^{* *}$ & $-.809^{* *}$ & $-.792^{* *}$ & .120 & .127 & .129 & .370 & .381 & .371 \\
\hline Age at birth of child & $.065^{*}$ & .051 & .046 & .013 & .004 & .003 & -.057 & -.049 & -.048 \\
\hline$<12$ years of school & $-.484^{* *}$ & $-.490^{* *}$ & $-.443^{* *}$ & -.051 & -.041 & -.038 & -.181 & -.159 & -.164 \\
\hline$>12$ years of school & .165 & .149 & .164 & $.292^{* *}$ & $.248^{*}$ & $.246^{*}$ & .127 & .160 & .175 \\
\hline Other family income (log) & $-.089^{* *}$ & $-.089^{* *}$ & $-.088^{* *}$ & .021 & .018 & .019 & .079 & .083 & .081 \\
\hline Last wage (log) & $1.394^{* *}$ & $1.329^{* *}$ & $1.323^{* *}$ & .200 & .192 & .192 & -.222 & -.239 & -.236 \\
\hline Missing wage & $-.617^{* *}$ & $-.550^{*}$ & $-.585^{* *}$ & -.051 & -.016 & -.024 & .093 & .059 & .070 \\
\hline Plan to work at age 35 & .200 & .213 & .212 & $.228^{*}$ & $.250^{* *}$ & $.245^{* *}$ & -.008 & -.012 & .004 \\
\hline $\begin{array}{l}\text { In predominantly female } \\
\text { occupation }\end{array}$ & -.047 & - & - & .054 & - & - & -.011 & - & - \\
\hline $\begin{array}{l}\text { Specific vocational } \\
\text { preparation }\end{array}$ & - & $.093^{*}$ & $.111^{* *}$ & - & .072 & .074 & - & -.079 & -.084 \\
\hline $\begin{array}{l}\text { Many part-year female } \\
\text { workers }\end{array}$ & - & .284 & $.309^{*}$ & - & -.236 & -.230 & - & -.012 & -.025 \\
\hline $\begin{array}{l}\text { Many part-time female } \\
\text { workers }\end{array}$ & - & $-.366^{* *}$ & $-.364^{* *}$ & - & .167 & .165 & - & -.056 & -.047 \\
\hline $\begin{array}{l}\text { Many mothers in the } \\
\text { occupation }\end{array}$ & - & - & $.224^{*}$ & - & - & .044 & - & - & -.088 \\
\hline Number of cases & 1,158 & 1,158 & 1,158 & 661 & 661 & 661 & 349 & 349 & 349 \\
\hline $\begin{array}{l}\text { Number of women who } \\
\text { returned to work }\end{array}$ & 497 & 497 & 497 & 312 & 312 & 312 & 121 & 121 & 121 \\
\hline$\chi^{2}$ & 101.52 & 105.25 & 105.11 & 51.73 & 59.23 & 59.58 & 51.73 & 59.23 & 59.58 \\
\hline Degrees of freedom & 11 & 13 & 14 & 23 & 27 & 29 & 23 & 27 & 29 \\
\hline
\end{tabular}

${ }^{*} p \leq .05 \quad{ }^{* *} p \leq .01$

a Models of return within 3 months estimated with logistic regression.

b Models estimated with a single piece-wise constant, exponential hazard model.

or after the first birth. This is consistent with results obtained by Gwartney-Gibbs (1987). Perhaps women's employment in primarily female occupations has little relationship with their family responsibilities, but is a function of employer discrimination and/or childhood socialization. However, this result is also consistent with the existence of competing effects that cancel each other out, or there may be no effect of sex composition of the occupation. In all the theoretical formulations on this topic, percent female acts as a proxy for other characteristics of the occupation, like ease of exit and re-entry, flexible work schedules, or social support for women on the job. We can examine some of these characteristics directly.

\section{Convenience of Combining Work and Motherhood}

We hypothesized that the difficulties of combining work and motherhood or impending motherhood could push women out of the work force during pregnancy and after the birth. During pregnancy, only strength requirements of the job had a significant effect on exits from work (Table 2). Strength requirements show the same pattern during the last trimester, but the coefficient is smaller and not significant. Effects for the variety of physical demands in the occupation, the prevalence of part-year or part-time employment in the occupation, or the presence of mothers in the occupation were not significant. 
Table 4. Effect of Selected Independent Variables on Women's Return to Work Within Three Months Following First Birth, by Women's Plans for Work: NLSY Women Employed in Year Before First Birth, 1979-1985

\begin{tabular}{|c|c|c|c|c|c|c|}
\hline \multirow[b]{2}{*}{ Independent Variable } & \multicolumn{3}{|c|}{$\theta-6 \mathrm{Menths}$ of Gestation } & \multicolumn{3}{|c|}{ 6-9 Months of Gestation } \\
\hline & Model 1 & Model 2 & Model 3 & Model 1 & Model 2 & Model 3 \\
\hline Constant & -3.444 & -3.168 & -3.159 & -1.300 & -1.878 & -2.058 \\
\hline Black & .061 & .081 & .082 & .463 & .443 & .483 \\
\hline Hispanic & .303 & .315 & .312 & -.012 & -.017 & .064 \\
\hline Not married at birth of child & $-.764^{*}$ & $-.714^{*}$ & $-.712^{*}$ & -1.061 & -.971 & -.933 \\
\hline Woman's age at birth of child & .078 & .057 & .055 & .041 & .035 & .021 \\
\hline$<12$ years of school & $-.512^{* *}$ & $-.503^{* *}$ & $-.497^{* *}$ & -.451 & $-.544^{*}$ & -.442 \\
\hline$>12$ years of school & .219 & .200 & .202 & -.002 & -.048 & -.007 \\
\hline Other family income (log) & -.049 & -.048 & -.051 & $-.165^{* *}$ & $-.160^{* *}$ & $-.152^{* *}$ \\
\hline Last wage $(\log )$ & $1.646^{* *}$ & $1.509^{* *}$ & $1.509^{* *}$ & $1.033^{* *}$ & $1.097^{*}$ & $1.081^{* *}$ \\
\hline Missing wage & $-.823^{*}$ & $-.703^{*}$ & $-.719^{* *}$ & -.316 & $-.395^{* *}$ & -.439 \\
\hline In predominantly female occupation & -.163 & - & - & .117 & - & - \\
\hline Specific vocational preparation & - & .090 & .093 & - & .107 & $.139^{*}$ \\
\hline Many part-year female workers & - & .142 & .159 & - & $.502^{*}$ & $.509^{*}$ \\
\hline Many part-time female workers & - & $-.472^{* *}$ & $-.492^{* *}$ & - & -.111 & -.065 \\
\hline Presence of mothers in the occupation & - & - & .096 & - & - & $.409^{* *}$ \\
\hline Number of cases & 720 & 720 & 720 & 438 & 438 & 438 \\
\hline Number of women who returned to work & 321 & 321 & 321 & 174 & 174 & 174 \\
\hline$\chi^{2}$ & 88.71 & 96.29 & 95.41 & 24.57 & 28.05 & 29.19 \\
\hline Degrees of fredom & 10 & 12 & 13 & 10 & 12 & 13 \\
\hline
\end{tabular}

${ }^{*} p \leq .05 \quad{ }^{* *} p \leq .01$

How do these measures of the ease of combining work and family affect returns to work after childbirth? Table 3 shows that these measures are significant only for returns to work within the first three months after the birth. Model 3 shows that women in occupations with opportunities for part-year work are more likely to return to work within three months of the birth, as are women in occupations with a relatively high proportion of mothers. But women in occupations with relatively many part-time female workers are less likely to return within three months. Most scholars agree that working part-time is a common strategy for combining work and childrearing and we expected occupations with relatively large proportions of part-time female workers to attract and retain women, especially mothers with very young children. Perhaps the flexibility these occupations offer to mothers is overshadowed by relatively low pay, poor benefits (including maternity leave), and competing alternatives common to these occupations.

Model 3 also shows that women in occupations that employ relatively many mothers with young children are more likely to return to work within the first three months following the birth. The presence of many women with young children in the occupation may provide social support to the young mother, or it may signal something about the flexibility of the work schedule, both of which make working easier for a new mother. The larger the proportion of an occupation's labor force who are mothers of young children, the more accommodations employers may have made to help their workers combine their two roles.

\section{Opportunity Cost of Labor Force Withdrawal}

We hypothesized that the higher the opportunity costs of labor force withdrawal, the less likely women are to withdraw from the labor force early in pregnancy and the more likely they are to return to work relatively soon after birth. Tables 2 and 3 show the expected effects for the three primary indicators of the opportunity cost of staying home: wages, specific vocational preparation, and education. Other family income indexes the 
woman's ability to pay the costs of labor force withdrawal, and so should increase the likelihood that she leaves early in pregnancy and returns slowly after the birth.

These measures are generally powerful predictors of women's employment near the first birth, but their effects are strongest for the decision to remain in the labor force through the first six months of pregnancy (Table 2), and to return to work within three months of the birth (Table 3 ). In the last trimester, both specific vocational preparation and last wage tie women to their jobs, but neither education nor other family income have significant effects. None of these measures affect returns to work more than three months after the birth, with the exception of education. Felmlee (1984) also found that high wages on a job lowered rates of leaving during pregnancy.

Women with some college education are no more likely to return to work during the first three months after the birth than women with a high school diploma (Table 3). But college-educated women are more likely to return to work within 3-11 months, given that they did not return before three months. College-educated women breastfeed their infants at much higher rates than do women with less schooling (Haaga 1989). Hence, college-educated women may place an especially high value on remaining at home during their child's first months and delay a return to work to breastfeed their children. If education generally increases women's chances of working, but decreases their chances of working while very young children are present, as Leibowitz (1974) has suggested, then the lack of effect on returns within the first three months may reflect these conflicting effects. When the children are older, the pull into the labor force of high levels of education seems to reassert itself.

Women who are high-school dropouts are significantly less likely than women with more schooling to return to work within three months after the birth (Table 3). These women are less likely to have jobs that offer maternity leave and so take leave without pay. These women may be less attached to their employers and face a wider array of relatively unattractive alternatives than do women with more schooling.

\section{Effect of Women's Preference for Employment Over the Long Run}

Our last hypothesis focuses on the interaction between long-run work preferences and other factors in determining exits from employment dur- ing pregnancy and returns to work after the first birth. Table 2 shows a significant negative main effect of preference for employment at age 35 on chances of leaving work during the third trimester of pregnancy. Table 3 shows that women who plan to work at age 35 are more likely to return to work during the child's first year (although the coefficient is not statistically significant for returns within three months). This measure reflects work commitment: Preferring to work long-term increases the costs to the woman's career of withdrawing from the labor force and so increases the chances of returning to work.

Following Rexroat and Shehan (1984), we hypothesize that women who prefer to hold a job over the long run will be influenced less by their current situations than will those who prefer to stay at home. Thus, we expect smaller effects of job convenience and need for the income for the work-committed than for women who prefer to remain at home. Results of a likelihood-ratio test indicate a statistically significant interaction between women's occupational and individual characteristics and her work commitment for returns to work during the first three months following the birth, but not for any other period. For this reason, we consider in more detail only the first three months after the birth.

Table 4 suggests that the work decisions of new mothers with low levels of work commitment depend somewhat more on current financial pressures than do those of women with a long-term commitment to employment. The negative effect of being unmarried on employment immediately following the first birth is a little larger for women who prefer to remain at home than for those who prefer to work over the long run. Marital status reflects eligibility for transfer income through AFDC, an option less often available to married mothers. However, the difference in the coefficients is not statistically significant. Other family income affects employment decisions only for women who do not plan to hold a job over the long run.

Table 4 also shows that the entire effect of presence of mothers in the woman's occupation results from its importance for women who prefer to remain at home; this measure of convenience has no effect for women who prefer employment. Another measure of convenience, presence of a large number of part-year female employees, has a significant positive effect for women with low levels of work commitment, but is not significant for highly committed women. 
Availability of part-time employment, another measure of convenience, has no impact on women who prefer not to work, and a significant negative effect for work-committed women. These occupations frequently do not offer maternity leaves or other job benefits and are probably easier to leave and re-enter. Perhaps women planning to work over the long run leave these jobs and return later to other similar jobs, whereas women without long-run work plans hope to leave the work force soon anyway. Specific vocational preparation for the occupation has a significant effect on returns to work only for women who do not want to hold a job over the long run. These women might be especially valuable employees whose bosses make adjustments to keep them. This increased "convenience" apparently ties some of these uncommitted workers to the occupation, but has no effect on women with longrun preferences for employment. These differences in the coefficients for the measures of financial need and convenience between women with and without plans to work over the long run are statistically significant at .10 or better.

\section{When Individual and Occupational Characteristics Matter}

Tables 2 and 3 indicate that although a number of individual and occupational characteristics affect women's labor force participation during the first six months of pregnancy and in the first three months following the birth, these factors have very little effect on women's employment probabilities in the last trimester of pregnancy or three or more months following the birth.

Health and medical problems may be overriding considerations late in pregnancy, weakening the effects of the variables in our models. But the lack of effect for returns to work after the first three months must arise from different causes. We suggest the following possibilities. The longer women remain away from work after a birth, the greater the chance they will return to a different job. Factors like specific vocational preparation become less important in predicting employment the longer women remain out of the labor force. The woman's last wage before the birth becomes less relevant for predicting her wage at a new job than for predicting wage at the same job. Since all of our independent variables measure the situation at or before the birth, they become weaker predictors in later periods in part because they do not reflect the woman's current situation.

\section{DISCUSSION}

We examine women's employment choices at a point of maximum conflict between work and family roles - the first pregnancy and birth. We test the general hypothesis that traditionally female occupations attract women because they are easy to combine with motherhood, and therefore retain workers prior to and following a birth. Some authors have argued that predominantly female occupations attract women because they are easy to exit when children are born and to re-enter later. However, we find no effect of the sex composition of the occupation, which could result from the operation of these competing effects or could signify that the sex composition of the occupation has no influence on the employment of pregnant women and new mothers.

Second, we tested hypotheses derived from the argument that occupations retain women with children either by making it easy for women to combine work and parenting or by making it costly for women to leave the labor force (or, alternatively, by making it profitable for women to remain at work). We examined characteristics of occupations that reflect the "convenience" of working and "costs" of not working. Our models also include individual characteristics that reflect the cost of staying at home.

Women respond to both convenience and costs in deciding how long to work during pregnancy and when to return to work after the child is born. The greater the rewards from working, the slower women are to leave their jobs during pregnancy and the sooner they return to work after the birth. The same pattern is observed for occupational characteristics that reflect convenience, although the particular measures that are important differ for pregnancy and the postnatal period. Measures reflecting both convenience and costs tend to have their strongest effects in the first six months of pregnancy and the first three months following the birth.

Finally, we tested the hypothesis that women who are committed to the work force over the long run would respond differently to characteristics of their occupations and to their own circumstances than would women who preferred not to work over the long run. We found some support for this hypothesis. Our measures of the convenience of combining work and motherhood tend to have stronger effects for women who do not plan to work long-term, as does specific vocational preparation, a measure of the cost of labor force withdrawal. None of the convenience 
measures have any impact on the employment decisions of women who prefer work to homemaking.

These results carry implications for the workings of labor markets, for women's job and career choices, and for occupational segregation, but caution is warranted. A number of reasons for caution exist. First, the process that matches workers to jobs is complex and ongoing. Some exits from employment are involuntary, and employers may more often layoff - or even fire pregnant women than women who are not expecting a child. Some women, no doubt, do not consider future motherhood and its stresses when deciding to take a job. Some women think through the kind of life they want to lead and make plans to achieve their goals. Some succeed, but events intervene, opportunities arise (or fail to materialize), and people change their minds. So the connections between women's plans and later behavior weaken. Women may chose occupations for any number of reasons, and then find when they begin their families that their occupations have high (or low) costs of labor force withdraw$\mathrm{al}$, and are convenient (or inconvenient) to combine with motherhood. Although predominantly female occupations may be relatively easy to combine with motherhood for the average woman, women who choose - or remain in -more demanding occupations may have unmeasured characteristics - an ability to handle stress, or a husband with a low-demand job - that enable them to combine work with family responsibilities. This selectivity would attenuate the effects of occupational characteristics on the hazards of leaving and returning to employment. Also, we do not distinguish between women who work full-time and those who work part-time, nor between women who return to the same job (or employer) and those who do not. Future research should address these issues.

Finally, although we model employment decisions near a birth as determined by occupational characteristics and characteristics of the woman, some of these variables are - to some extent endogenous. The argument that women choose occupations in anticipation of working or not working after they have children suggests that occupational characteristics are endogenous for some. And women's commitment to work may determine their choice of occupations - those who intend to work over the long run may choose occupations that are easy to combine with motherhood and invest more in education and jobspecific training. Because our models hold con- stant education, training, and some occupational characteristics, they may underestimate the total effect of work commitment on employment near a birth.

In spite of these caveats, we examine some implications of our results for occupational segregation, for women's employment, and for employment and family-leave policies. If some occupations have characteristics like flexible work schedules, short hours, or absence of extensive travel that make them relatively easy to combine with childrearing, as long as women have primary responsibility for childrearing then these occupations may be more attractive to women than to men, at least on average. Women may be willing to trade off earnings, chances for advancement, or interesting work for this convenience, as Filer (1985) and Hudis (1976) have argued. Some women may actively seek out these occupations in anticipation of motherhood, so that these occupations may differentially retain women with children. Either process should lead a concentration of women in these occupations relative to occupations that are more difficult to combine with parenthood. And either process would contribute to occupational segregation by sex.

Our results suggest that this process of recruitment of women into "convenient" occupations operates only for women who plan not to work over the long run. Women who prefer to be employed show little effect of occupational characteristics reflecting the ease of combining work and motherhood. The proportion of young women who say that they prefer to hold a job later in life (and, we presume, over the long-run) has risen dramatically over the last several decades, so our results imply that convenience for mothers has become less important in drawing women into traditionally female occupations. ${ }^{10}$ In addition, some recent evidence has suggested that those most likely to hold "convenient" occupations are males without dependent children (Glass and Camarigg 1991).

Our results also imply changes in women's lifetime labor supply. As women's preference to work over the long run increases, the more women will be willing to combine work and childcare during the stressful period when children are

\footnotetext{
${ }^{10}$ Our findings may also understate the impact of job convenience on women's employment decisions around the first birth if convenient occupations pay less than others, since our analyses hold constant the effect of wages.
} 
young. Time/budget studies suggest that employed mothers of young children fulfill both roles in part by getting less sleep and enjoying less leisure than other women or men (Stafford 1980). Although some women who remain at work during this period might prefer to stay at home with their babies if they had only the present to consider, retaining their jobs is in their best interests in the long run - if not the short run. As employment of women over most of their adult lives becomes more common, women's wages will rise (Smith and Ward 1989) and access to jobs with other benefits should improve as well. Our results suggest that women's willingness to work when they are eight or nine months pregnant, and when they have a two- or three-monthold baby depends both on the rewards they get from the job, and the ease with which they can combine work with pregnancy or parenting.

As more employers invest in their female employees and expect them to remain at work about as long as their male employees, they must help women meet their obligations to job and family. Other research has suggested that having a flexible schedule makes a tremendous difference (Glass and Camarigg 1991), as does having a supportive supervisor. As more mothers of very young children return to work, arrangements for the care of these children, their health, education, and social and emotional development become increasingly important.

SONALDE DESAI is an associate in the Research Division at The Population Council in New York. Her work focuses on the interrelationship between women's work and childrearing responsibilities in both developed and undeveloped countries. Recently, she has studied the impact of maternal employment on child development in the United States. She is currently examining the validity of applying neoclassical models of household economics to the family systems in developing countries.

LINDA J. WAITE is Professor of Sociology at the University of Chicago, Research Associate in the Population Research Center, the Ogburn/Stouffer Center, NORC, and Research Associate in the Population Research Center, The RAND Corporation. She is author, with Frances Goldscheider, of New Families, No Families? The Transformation of the American Home (University of California Press, 1991). She is currently examining the relationship between higher education and family formation (with Ross M. Stolzenberg), social exchange networks of older adults (with Merril Silverstein), widowhood and mortality in older couples (with Lee Lillard), and the process of union formation and dissolution among young adults (also with Lillard).
APPENDIX. Definition of Variables

Individual Characteristics

Racelethnicity. Based on women's primary self-identification.

Marital Status at Childbirth. From marital and birth history.

Age. In completed years.

Education. Highest grade completed as of first birth. Omitted category is completed grade 12 .

Other Family Income. In the calendar year before the birth. Excludes woman's wage income and AFDC payments.

Wage. Hourly wage in the last job held during pregnancy, set to mean for women with missing wage data.

Missing Wage. $1=$ missing, 0 otherwise.

High Work Commitment. 1 = respondent plans to work at age 35 . Based on question asked in the interview before birth.

\section{Occupational Characteristics}

Occupation.Three-digit census category. Some occupations are divided into several sub-categories based on the three-digit industry code and one-digit class of worker code.

Predominantly Female Occupation. $1=$ at least 75 percent all incumbents in the occupation are female.

Presence of Mothers in the Occupation. $1=$ at least 6.5 percent of all incumbents in occupation are women with a child under three.

Many Female Part-Time Workers. $1=$ at least 22 percent of the female incumbents in occupation worked less than 30 hours per week.

Many Female Part-Year Workers. $1=$ at least 35 percent of the female incumbents in occupation work less than 48 weeks per year.

Specific Vocational Preparation. Amount of time required to learn the techniques and to develop facility needed for average performance in a specific job-worker situation. Consists of vocational education, apprentice training, in-plant training, on-the-job training, essential experience in other jobs. Scale ranges from 1 (short demonstration only) to 9 (Over 10 years).

Strength Requirements. Scale ranging from 1 (sedentary work) to 5 (very heavy work) based on strength required in any of these activities: lifting, carrying, pushing and pulling.

Physical Demands. Based on whether the worker is typically engaged in climbing and/or balancing; stooping, kneeling, crouching and/or crawling; reaching, handling, fingering and/or feeling; talking and/or hearing; and seeing. The scale counts the variety of physical demands and ranges from 0 to 5 , based on the number of activities.

\section{REFERENCES}

Allison, Paul D. 1982. "Discrete Time Methods for the Analysis of Event Histories." Pp. 61-98 in Sociological Methodology, edited by S. Leinhards. San Francisco: Jossey Bass.

Beller, Andrea. 1985. "Changes in Sex Composition of U.S. Occupations." The Journal of Human Resources 20:235-50.

Bielby, Denise Del Vento and William T. Bielby. 
1984. "Work Commitment, Sex-Role Attitudes and Women's Employment." American Sociological Review 49:234-47.

Cramer, James C. 1980. "Fertility and Female Employment: Problems of Casual Direction." American Sociological Review 45:167-90.

Darian, Jean C. 1975. "Convenience of Work and the Job Constraint of Children." Demography 12:245-55.

Felmlee, Diane. 1984. "A Dynamic Analysis of Women's Employment Exits." Demography 21:171-83.

Filer, Randolph. 1985. "Male-Female Wage Differences: The Importance of Compensating Differentials." Industrial and Labor Relations Review 38:426-37.

Flinn, D. J. and James J. Heckman. 1982. "Models for the Analysis of Labor Force Dynamics." Advances in Econometrics 1:35-95.

Gerson, Katherine. 1985. Hard Choices: How Women Decide About Work, Career and Motherhood. Berkeley: University of California Press.

Glass, Jennifer and Valerie Camarigg. 1991. "Gender, Parenthood and Job-Family Compatibility." Department of Sociology, Notre Dame University. Unpublished manuscript.

Guttmacher, Alan F. 1956. Pregnancy and Birth. New York: New American Library.

Gwartney-Gibbs, Patricia. 1987. "Women's Work Intensity and the Origins of Occupational Sex Segregation." Paper presented at the meetings of the American Sociological Association, 21 Aug., Chicago.

Haaga, John. 1989. "The Revival of Breastfeeding in the United States, 1963-81." The RAND Corporation, Santa Monica, CA. Unpublished manuscript.

Heckman, James J. and Robert J. Willis. 1977. "A Beta-Logistic Model for the Analysis of Sequential Labor Force Participation of Married Women." Journal of Political Economy 85:27-58.

Hout, Michael. 1978. “The Determinants of Marital Fertility in the United States, 1960-1970: Inferences from a Dynamic Model." Demography 15:139-59.

Hudis, Paula M. 1976. "Commitment to Work and to Family: Marital-Status Differences in Women's Earnings." Journal of Marriage and the Family 267-78.

Jacobs, Jerry A. 1989. "Long-Term Trends in Occupational Segregation by Sex." American Journal of Sociology 95:160-73.

Klerman, Jacob Alex. 1990. "Work Around Childbirth: Correlated Hazards." Paper presented at the meetings of the Econometric Society, 28 Dec., Washington, DC.

Leibowitz, Arleen. 1974. "Education and Home Production." American Economic Review 64:243-50.

Leibowitz, Arleen, Linda J. Waite, and Christina Witsberger. 1988. "Child Care for Preschoolers: Differences by Child's Age." Demography 25:205-20.

Moen, Phyllis and Ken R. Smith. 1986. "Women at Work: Commitment and Behavior Over the Life Course." Sociological Forum 1:450-74.

Polachek, Solomon. 1979. “Occupational Segrega- tion Among Women: Theory, Evidence and a Prognosis." Pp. 137-57 in Women in the Labor Market, edited by C. Lloyd, E. Andrews, and C. Gilroy. New York: Columbia University Press. . 1987. "Occupational Segregation and the Gender Wage Gap." Population Research and Policy Review 6:47-67.

Reskin, Barbara F. and Heidi Hartmann. 1986. Women's Work, Men's Work: Sex Segregation on the $J o b$. Washington, DC: National Academy Press.

Rexroat, Cynthia and Constance Shehan. 1984. "Expected and Actual Work Roles of Women." American Sociological Review 49:349-58.

Roos, Patricia A. and Donald J. Treiman. 1980. DOT Scales for the 1970 Census Classification. Pp. 336389 in Work, Jobs and Occupations: A Critical Review of the Dictionary of Occupational Titles, edited by A. Miller, D. Treiman, P. Cain, and P. Roos. Washington, DC: National Academy Press. Rosenfeld, Rachel A. and Kenneth I. Spenner. 1986. "Women's Work and Women's Careers: A Dynamic Analysis of Work Identity in the Early Life Course." Pp. 285-305 in Social Structure and Human Lives, edited by M. A. Riley. Newbury Park, CA: Sage.

. 1990. "Occupational Sex Segregation and Careers." Department of Sociology, University of North Carolina. Unpublished manuscript.

Ross, Catherine R. 1987. "The Division of Labor at Home." Social Forces 65:816-33.

Schwartz, Felice. 1989. "Management Women and the New Facts of Life." Harvard Business Review 67:65-76.

Shaw, Lois B. and David Shapiro. 1987. "Women's Work Plans: Contrasting Expectations and Actual Work Experience." Monthly Labor Review 110:7-13.

Smith, James P. and Michael Ward. 1989. "Women in the Labor Market and in the Family." Journal of Economic Perspectives 3:9-23.

Spitze, Glenna. 1986. "The Division of Task Responsibility in U.S. Households: Longitudinal Adjustments to Change." Social Forces 64:689-701.

Stafford, Frank P. 1980. "Women's Use of Time Converging with Men's." Monthly Labor Review 103:58-60.

Temme, Lloyd V. 1975. Occupations: Meanings and Measures. Washington, DC: Bureau of Social Science Research.

Tuma, Nancy B. 1980. Invoking RATE. Menlo Park, CA: SRI International.

Tuma, Nancy B. and Michael T. Hannan. 1984. Social Dynamics: Models and Methods. Orlando: Academic Press.

U.S. Bureau of the Census. 1986. Fertility of American Women (Current Population Report, Series P20, No. 406). Washington, DC: U.S. Government Printing Office.

Wolf, Wendy and Rachel Rosenfeld. 1978. "Sex Structure of Occupations and Job Mobility." Social Forces 56:823-44. 